American Journal of Environmental Sciences 6 (5): 442-448, 2010

ISSN 1553-345X

(C) 2010 Science Publications

\title{
Optimizing Coagulation Process for Low to High Turbidity Waters Using Aluminum and Iron Salts
}

\author{
${ }^{1}$ Akbar Baghvand, ${ }^{2}$ Ali Daryabeigi Zand, ${ }^{1}$ Nasser Mehrdadi and ${ }^{1}$ Abdolreza Karbassi \\ ${ }^{1}$ Department of Environmental Engineering, Faculty of Environment, \\ University of Tehran, Tehran, Iran \\ ${ }^{2}$ Environmental Sciences Research Institute, Shahid Beheshti University, \\ GC, Tehran, Iran
}

\begin{abstract}
Problem statement: Turbid waters, containing colloidal particles, are normally treated by coagulation-flocculation followed by clarification. Ferric chloride and alum, which are the most common types of coagulants in water treatment plants of Iran as well as many other countries, were investigated with the aim of determining their capabilities to reduce turbidity of drinking water. Turbidity was added as kaolin. Optimization of coagulation process may assure removal of turbidity to a level below water quality standards in most cases. Approach: In this study, the effectiveness of aluminum sulfate and ferric chloride was evaluated at different $\mathrm{pH}$ values and coagulant dosage to find optimal operational conditions for low to high turbidity waters. The influence of lime, as a coagulant aid, on coagulation process was also studied. A set of jar test experiments was conducted to find the optimal $\mathrm{pH}$ and coagulant dosage. Results: Results demonstrated that coagulation process can assure turbidity removal from low to medium turbidity waters effectively, using relatively low levels of aluminum sulfate and ferric chloride $\left(10-20 \mathrm{mg} \mathrm{L}^{-1}\right)$. Turbidity removal efficiency still remained high when the initial turbidities of water were increased to 500 and 1000 NTU. Conclusion/Recommendations: Results showed that turbidity removal is dependent on $\mathrm{pH}$, coagulant dosage, as well as initial turbidity of water for both used coagulants. The highest turbidity removal efficiency was within $82.9-99.0 \%$ for alum and $92.9-99.4 \%$ for ferric chloride over the applied range of turbidity. Turbidity removal efficiency was higher for ferric chloride compared to aluminum sulfate at optimum conditions. Both applied coagulants demonstrated promising performance in turbidity removal from water. The results of the current study can be used as a baseline data for drinking water treatment facilities which uses these two types of coagulants.
\end{abstract}

Key words: Coagulation process, turbidity removal, ferric chloride, aluminum sulfate, synthetic water

\section{INTRODUCTION}

Rapid growth of population, urbanization and industrial as well as agricultural activities have increased water demand, particularly in recent decades. Water treatment industry is among the most important industries in many countries such as Iran. Coagulation, flocculation, sedimentation, filtration and disinfection are the most common treatment processes used in the production of drinking water. Coagulation/flocculation processes are of great importance in solid-liquid separation practice (Yukselen and Gregory, 2004). The coagulation process is used to destabilize colloidal material in water by the addition of a chemical agent. It requires rapid mixing to quickly disperse the coagulant and subsequently flocculation process. Flocculation is the formation of aggregates of the destabilized colloids and requires gentle mixing to allow effective collisions between particles to form heavy flocs which can be removed from water by settlement.

Colloids are small suspended particles in water which cannot be settled or removed naturally due to their light weight and stability. These particles pose some degree of stability and cause water turbidity. Turbidity may contain many contaminants like pathogenic organisms. Many pollutants of concern to human health e.g., metals or some synthetic organic chemicals are also associated with turbidity. Thus, effective turbidity elimination is necessary to ensure removal of many health-related contaminants. In addition effective removal of turbidity may ease subsequent water treatment processes.

Aluminum and iron salts are the most widely used coagulants in Iran as well as many other countries in the drinking water industry. They are mainly used in Iran because of their effectiveness, accessibility and low

Corresponding Author: A. Daryabeigi Zand, Environmental Sciences Research Institute, Shahid Beheshti University, GC, Environment 1983963113, Tehran, Iran Tel: +98 2122431971 Fax: +98 2122431973 
Am. J. Environ. Sci., 6 (5): 442-448, 2010

price. Findings on various coagulation processes have been reported in literature. Some of these include; studying the effect of dosage and mixing conditions on the flocculation of concentrated suspensions using polymeric coagulants (Ghaly et al., 2007; Faiku et al., 2010); coagulation of synthetic water by plant seeds (Diaz et al., 1999) and coagulation of low turbidity water using bentonite (Shen, 2005). Guida et al. (2007) used alum as coagulant to remove COD and Total Suspended Solids (TSS) from municipal wastewater samples. The coagulation experiments indicated that alum effectively removed COD (65\%) and TSS $(>75 \%)$ on the average values of COD using $150 \mathrm{mg} \mathrm{L}^{-1}$ aluminum sulfate at a pH range of 5-8 (Guida et al., 2005).

In this study two coagulants, namely ferric chloride and alum, which are the most common types of coagulants in water treatment plants of Iran, were investigated with the aim of determining their capabilities to reduce turbidity of drinking water. Their effectiveness was evaluated at different $\mathrm{pH}$ values and coagulant dosage to find optimal operational conditions for low to highly turbidity waters. The influence of lime, as a coagulant aid, in accompany with aluminum sulfate and ferric chloride was also studied. The interest in coagulation processes and therefore the removal of turbidity lies in the fact that colloids may directly or indirectly threaten the human health. The results of the current study can be used as the baseline data for drinking water treatment facilities which uses these two types of coagulants.

\section{MATERIALS AND METHODS}

Jar test experiments were conducted within a $\mathrm{pH}$ range of 4-8. Aluminum sulfate $\left(\mathrm{Al}_{2}\left(\mathrm{SO}_{4}\right)_{3} \cdot 18 \mathrm{H}_{2} \mathrm{O}\right)$ and ferric chloride $\left(\mathrm{FeCl}_{3}, 6 \mathrm{H}_{2} \mathrm{O}\right)$ were used in the current study, as the most common types of coagulants used in many water treatment plants. Distilled water was used in this study to avoid probable interference of any elements in water with turbidity removal. Desired turbidity was provided synthetically by kaolin powder. A calibration curve of the turbidity versus kaolin concentration was obtained. Sodium hydroxide and sulfuric acid were used for $\mathrm{pH}$ adjustment. Prepared samples were placed in a $1000 \mathrm{ml}$ beaker and stirred at $350 \mathrm{rpm}$ for $1 \mathrm{~min}$ (rapid mixing). The mixing speed was reduced to $30 \mathrm{rpm}$ for $20 \mathrm{~min}$ for flocculation (slow mixing). Within $5 \mathrm{~min}$ from the beginning of flocculation $\mathrm{pH}$ was checked and adjusted (if necessary) to keep the desired $\mathrm{pH}$ value \pm 0.05 units. Any floc formed was allowed to settle for $45 \mathrm{~min}$.
Table 1: Experimental characteristics for jar test experiments conducted in this study

\begin{tabular}{ll}
\hline Characteristics & Description \\
\hline Coagulants & Aluminum sulfate and ferric chloride \\
Coagulant dose range & $5-50\left(\mathrm{mg} \mathrm{L}^{-1}\right)$ \\
Coagulant aid (dose) & Lime $\left(5 \mathrm{mg} \mathrm{L}^{-1}\right)$ \\
pH range & $4-8$ \\
Initial turbidity & $10-1000(\mathrm{NTU})$ \\
Rapid mixing & $60 \mathrm{sec}$ at $350(\mathrm{rpm})$ \\
Slow mixing & 20 min at $30(\mathrm{rpm})$ \\
Settling & $45(\mathrm{~min})$ \\
\hline
\end{tabular}

Supernatant samples were taken from $20 \mathrm{~mm}$ below the water surface for turbidity measurements. Supernatant turbidity was measured with a HACH 2100A turbidimeter and expressed in Nephelometric Turbidity Units (NTU). Residual turbidity was used as the indicator of performance. The optimal $\mathrm{pH}$ and dose for turbidity removal with both aluminum sulfate and ferric chloride were attained by the jar test experiments. In addition, lime was also used in accompany with alum and ferric chloride at optimum $\mathrm{pH}$ values to investigate its influence on coagulation process and turbidity removal efficiency. All jar test experiments were conducted at room temperature because low temperature may have an adverse effect on coagulation and flocculation kinetics as suggested by Kang and Cleasby (1995). Experimental characteristics for the jar test experiments in this research were summarized in Table 1.

\section{RESULTS}

Figure 1 presents turbidity removal efficiency as a function of aluminum sulfate dose at $\mathrm{pH}$ range of 4-8. Initial turbidities of water samples were adjusted to be $10,50,100,200,500$ and 1000 NTU. Initial turbidities of 10 and 50 NTU, 100 and 200 NTU and 500 and 1000 NTU were respectively considered as low, medium and highly turbidity levels in water, based on the applied turbidity levels. However, this classification may be somewhat different in other texts. High initial turbidities were considered in this research because such high turbidities commonly occur in many stormwaters (Annadurai et al., 2004). Low turbidity waters are usually hard to coagulate due to low concentrations of stable particles and sometimes turbidity is synthetically added to the water to form heavier flocs which can be settled. However, in the current study the lowest applied turbidity (10 NTU) was not too low to disturb coagulation process. Figure 2 illustrates the effect of ferric chloride dose on turbidity removal at different $\mathrm{pH}$ values. Variations in turbidity removal under different scenarios are presented in Table 2. 
Am. J. Environ. Sci., 6 (5): 442-448, 2010

Table 2: Variation of turbidity removal after coagulation process due to addition of $5 \mathrm{mg} \mathrm{L}^{-1}$ lime (\%)

\begin{tabular}{|c|c|c|c|c|c|c|c|c|c|c|c|c|}
\hline \multirow[b]{3}{*}{ Dosage $\left(\mathrm{mg} \mathrm{L}^{-1}\right)$} & \multicolumn{6}{|c|}{ Coagulant } & \multicolumn{6}{|c|}{ Aluminum sulfate } \\
\hline & \multicolumn{6}{|c|}{ Variation $(\%)$ at $\mathrm{pH}=6$} & \multicolumn{6}{|c|}{ Variation $(\%)$ at $\mathrm{pH}=7$} \\
\hline & 5 & 10 & 20 & 30 & 40 & 50 & 5 & 10 & 20 & 30 & 40 & 50 \\
\hline \multicolumn{13}{|c|}{ Initial turbidity (NTU) } \\
\hline 10 & -8.3 & 0.0 & -11.1 & -18.2 & -5.0 & -25.0 & 0.0 & -33.3 & -60.0 & -57.1 & -16.7 & -16.7 \\
\hline 50 & -15.4 & -25.0 & -10.0 & -11.1 & 0.0 & -8.3 & -10.0 & -45.4 & -33.3 & 0.0 & -11.1 & 4.3 \\
\hline 100 & 3.0 & 5.6 & 5.0 & -4.2 & -8.6 & 4.6 & -1.6 & -9.1 & 5.6 & 4.8 & 5.3 & 36.8 \\
\hline 200 & 2.5 & 4.3 & 2.4 & 1.3 & 6.0 & 8.5 & -6.7 & -6.4 & 0.0 & 3.5 & 14.9 & 3.7 \\
\hline 500 & -21.7 & -21.5 & -13.4 & -8.7 & -10.5 & -9.5 & -22.2 & -29.1 & -28.5 & -31.1 & -27.3 & -26.1 \\
\hline \multirow[t]{3}{*}{1000} & -15.6 & -13.8 & -7.3 & -8.7 & -9.2 & -6.7 & -29.0 & -23.6 & -11.6 & -13.0 & -11.0 & -10.6 \\
\hline & \multicolumn{6}{|c|}{ Coagulant } & \multicolumn{6}{|c|}{ Ferric chloride } \\
\hline & \multicolumn{6}{|c|}{ Variation (\%) at $\mathrm{pH}=5$} & \multicolumn{6}{|c|}{ Variation $(\%)$ at $\mathrm{pH}=6$} \\
\hline 10 & -11.1 & 0.0 & -33.3 & 0.0 & 0.0 & -16.7 & -18.2 & -40.0 & -27.3 & -16.7 & -12.5 & -10.0 \\
\hline 50 & -16.7 & -66.7 & -33.3 & -37.5 & -37.5 & -33.3 & -25.0 & -40.0 & -50.0 & 0.0 & -14.3 & -25.0 \\
\hline 100 & -29.8 & -35.7 & -35.7 & -38.9 & -36.8 & -36.4 & -26.6 & -33.3 & -31.3 & -35.0 & -30.0 & -39.1 \\
\hline 200 & -26.6 & -30.5 & -29.6 & -25.5 & -37.5 & -39.3 & -26.4 & -33.6 & -26.8 & -21.6 & -32.3 & -28.8 \\
\hline 500 & -6.5 & -12.5 & -7.1 & -5.5 & -4.6 & -6.2 & -4.9 & -5.0 & 0.6 & 1.4 & 2.9 & 1.5 \\
\hline 1000 & -11.2 & -7.6 & -22.4 & -18.3 & -18.7 & -18.7 & -10.1 & -3.4 & -24.3 & -20.8 & -20.0 & -20.8 \\
\hline
\end{tabular}

\section{DISCUSSION}

The best performance of alum was observed at $\mathrm{pH}$ 7 over the selected range of turbidity but its performance decreased to some extent at $\mathrm{pH}$ values of 4,5 and 8. Coagulation efficiency of alum at $\mathrm{pH} 6$ was almost close to that of at $\mathrm{pH}$. The highest turbidity removal was attained at $\mathrm{pH} 7$ when $10 \mathrm{mg} \mathrm{L}^{-1}$ alum was used except for initial turbidity of 1000 NTU. The optimum alum dosage was higher $\left(20 \mathrm{mg} \mathrm{L}^{-1}\right)$ for initial turbidity of 1000 NTU which was the lowest required dosage obtained the highest turbidity removal. The best performance of alum in removing turbidity from water was obtained at $\mathrm{pH} 7$ following by $\mathrm{pH}$ 6. The coagulation efficiency of alum remained almost constant within the dosage range of $10-40 \mathrm{mg} \mathrm{L}^{-1}$ at $\mathrm{pH}$ range of 4-8 (Fig. 1). In other words, results showed that alum dosage range for good coagulation was almost wide in this study. However, over-dosing was observed for low to medium turbidity waters when 50 $\mathrm{mg} \mathrm{L}^{-1}$ alum was used. Turbidity removal efficiency was slightly decreased by increasing alum concentration from $40-50 \mathrm{mg} \mathrm{L} \mathrm{L}^{-1}$, e.g., turbidity removal decreased from $97.1-95.7 \%$ at $\mathrm{pH} 6$ (initial turbidity of $100 \mathrm{NTU}$ ). This reduction may be attributed to charge reversal and destabilization of colloidal particles due to overdosing as also suggested by Yukselen and Gregory (2004) and Shen (2005). Generally, aluminum and iron salts are rapidly hydrolyzed in water to give a range of products including cationic species, which can be absorbed by negatively charged particles and neutralize their charge. This is one mechanism whereby particles can be destabilized, so that flocculation can occur. Overdosing can disrupt this phenomenon, therefore fairly precise control of coagulant dosage should be considered in water treatment plants. At the optimum condition (optimal dose and $\mathrm{pH}$ ), turbidity removal efficiencies of alum were $98.5,99,98.3,82.9,86.3,84.3$ percent for initial turbidities of 10, 50, 100, 200, 500 and 1000 NTU, respectively. Results indicated that turbidity removal efficiency was varied by $\mathrm{pH}$, alum dose and initial turbidity of water. The obtained results are in accordance with those obtained by Volk et al. (2000) which were indicated that the $\mathrm{pH}$ of coagulation was the most influential parameter affect NOM removal from water (Volk et al., 2000). They also suggested that the amount of NOM removed from water is also dependent on the type of coagulant. They used aluminum and iron salts as coagulants in their jar test experiments. In coagulation study conducted by Annadurai et al. (2004) simultaneous removal of turbidity and humic acid from high turbidity synthetic raw water using another aluminum salt, i.e., Polyaluminum Chloride (PACl) was investigated (Annadurai et al., 2004). Simultaneous removal of both turbidity and humic acid from the high turbidity water was achieved at neutral $\mathrm{pH}$. They also suggested the $\mathrm{pH}$ value, initial turbidity and $\mathrm{PACl}$ dose as significant variables affect coagulation process. 
Am. J. Environ. Sci., 6 (5): 442-448, 2010

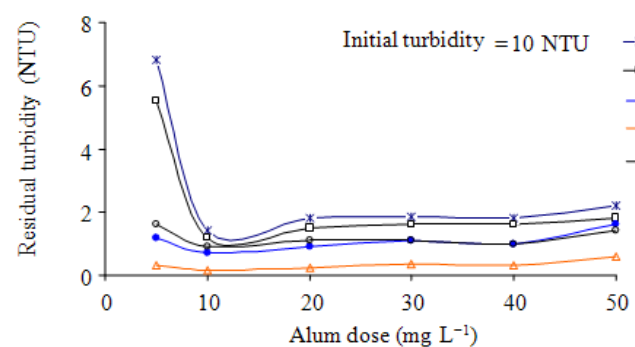

(a)

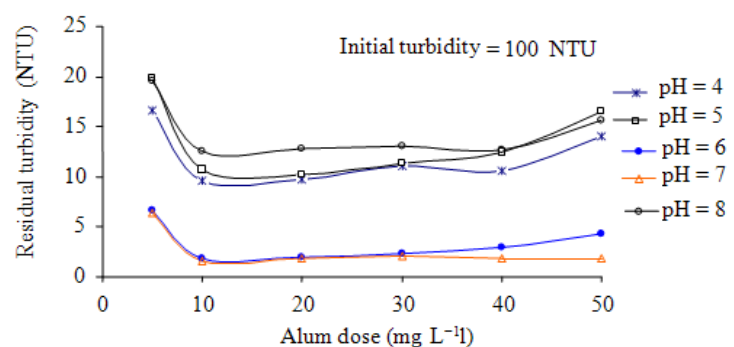

(c)

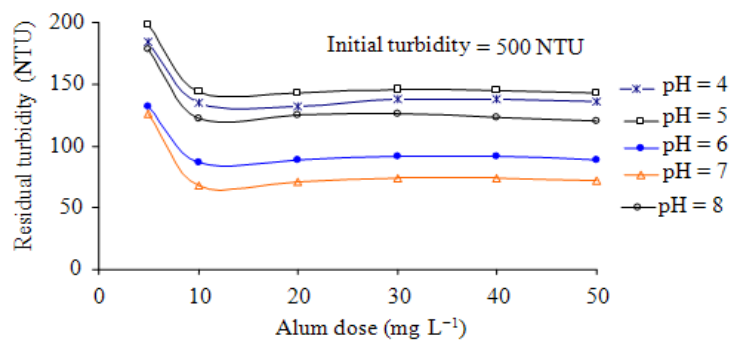

(e)

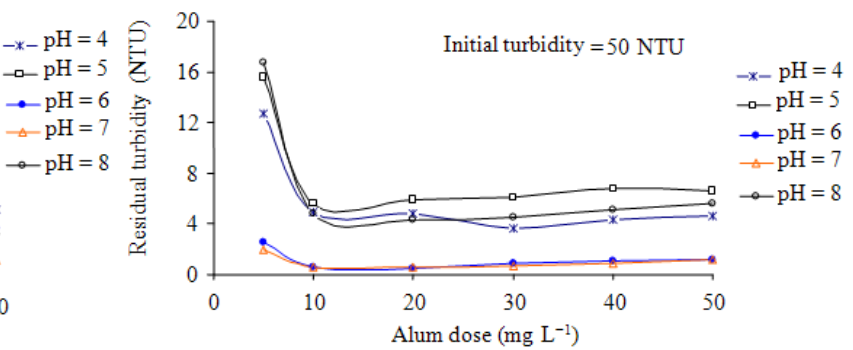

(b)

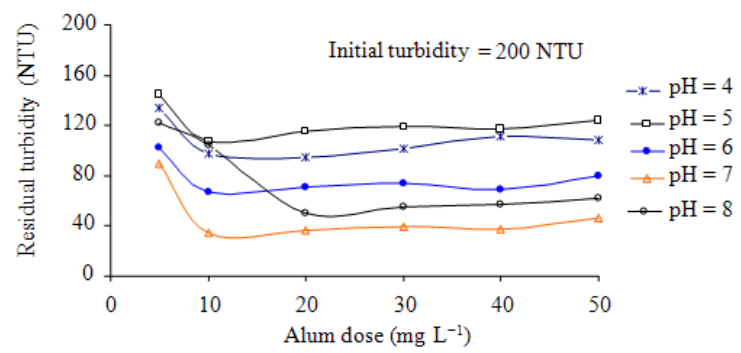

(d)

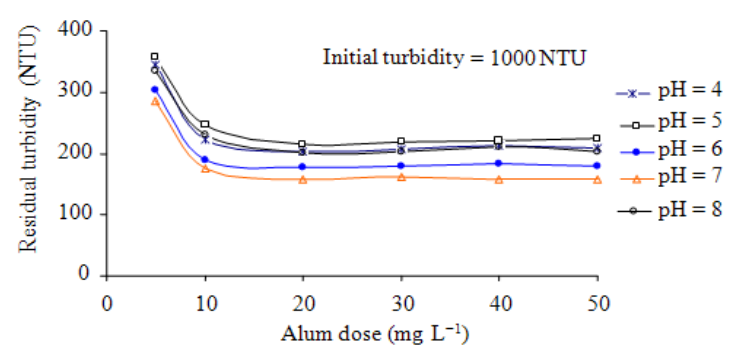

(f)

Fig. 1: Turbidity removal as a function of aluminum sulfate dose at $\mathrm{pH}$ range of 4-8

Results indicated that turbidity removal efficiency was decreased to some extent by increasing initial turbidity level from 100-200, 500 and 1000 NTU. Application of higher alum dosage range may improve turbidity removal from relatively high turbidity waters. However it should be considered that coagulation with alum may increase aluminum concentration in drinking water as reported in many texts (Driscoll et al., 1998). Aluminum in coagulated drinking water has been regarded as a subject of human and environmental health concern (Guida et al., 2007). Driscoll et al. (1998) observed that the use of alum can increase the total $\mathrm{Al}$ (III) concentration from $0.37 \pm 0.33 \mu \mathrm{mol} \mathrm{l}^{-1}$ in raw water to $1.8 \pm 0.33 \mu \mathrm{mol} \mathrm{\textrm {L } ^ { - 1 }}$ in filtered water (Driscoll et al., 1998). Alum human health hazards have been well documented. Using alternative aluminum based coagulants, like polyaluminium chloride, polyaluminium silica-chloride and polyaluminium ferric chloride are also to be further investigated in detail to improve coagulation efficiency as well as obtaining of minimum residual aluminum in treated water. Under-dosing was observed when $5 \mathrm{mg}$ $\mathrm{L}^{-1}$ ferric chloride was used over the applied range of turbidity. Turbidity removal efficiency was considerably increased by increasing ferric chloride dosage from 50-10 $\mathrm{m} \mathrm{L}^{-1}$ in all cases (Fig. 2).

The best performance of ferric chloride was observed at $\mathrm{pH} 5$ and subsequently $\mathrm{pH} 6$. The optimum coagulant dosage for initial turbidities of $10,50,100$ and $200 \mathrm{NTU}$ was obtained when $10 \mathrm{mg}$ $\mathrm{L}^{-1}$ ferric chloride was used. However, the highest turbidity removal efficiency for initial turbidities of 500 and 1000 NTU was achieved when 20 and $30 \mathrm{mg}$ $\mathrm{L}^{-1}$ ferric chloride was used, respectively. It should be noted that increase in ferric chloride concentration from $10-20 \mathrm{mg} \mathrm{L}^{-1}$ and from $20-30 \mathrm{mg} \mathrm{L}^{-1}$, respectively, for initial turbidities of 500 and 1000 NTU did not enhance turbidity removal considerably. 
Am. J. Environ. Sci., 6 (5): 442-448, 2010

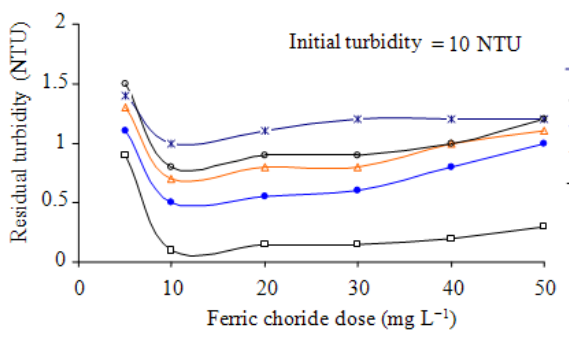

(a)

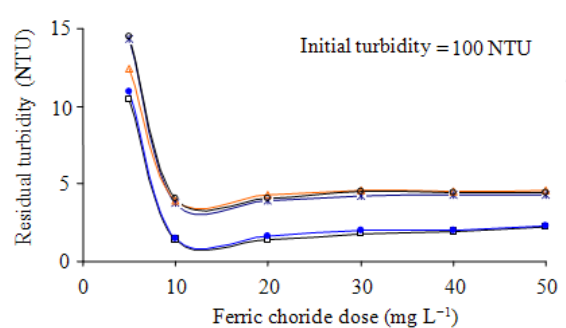

(c)

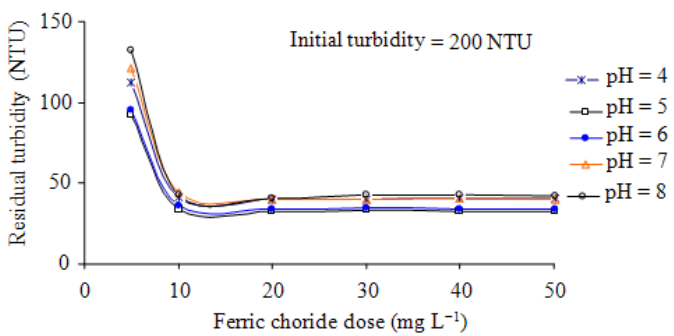

(e)

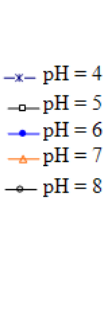

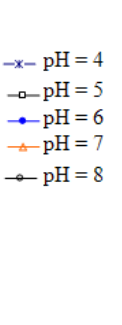

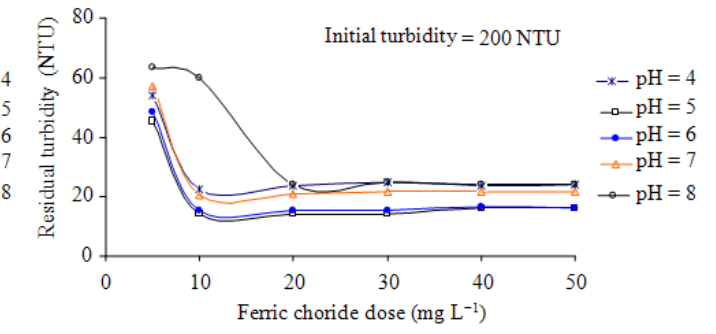

(d)

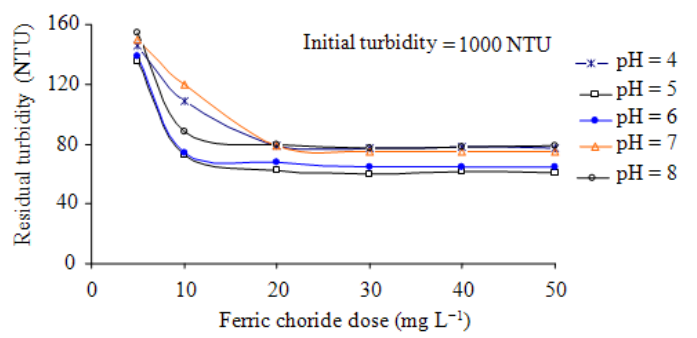

(f)

Fig. 2: Turbidity removal as a function of ferric chloride dose at $\mathrm{pH}$ range of 4-8

For instance, maximum turbidity removal efficiency for initial turbidity of $500 \mathrm{NTU}$ increased from $93.1-93.5 \%$ ( $0.4 \%$ enhancement) at optimal $\mathrm{pH} 5$, when $20 \mathrm{mg} \mathrm{L}^{-1}$ ferric chloride was applied instead of $10 \mathrm{mg} \mathrm{L}^{-1}$. Turbidity removal was almost stable at all dosages greater than $10 \mathrm{mg} \mathrm{L}^{-1}$ when $\mathrm{pH}$ was kept constant. Therefore optimal dosage of $10 \mathrm{mg} \mathrm{L}^{-1}$ ferric chloride can be selected over the applied range of turbidity except for initial turbidity of 1000 NTU. Based on the obtained results, the optimum ferric chloride dosage for initial turbidity of $1000 \mathrm{NTU}$ is considered to be $20 \mathrm{mg}$ $\mathrm{L}^{-1}$ in this study.

Over-dosing was also observed for low turbidity waters when $50 \mathrm{mg} \mathrm{L}^{-1}$ ferric chloride was used, similar to alum coagulant. Turbidity removal efficiency was slightly decreased by increasing ferric chloride concentration from $40-50 \mathrm{mg} \mathrm{L}^{-1}$ in low-turbid waters. Turbidity removal efficiencies of ferric chloride at the optimal $\mathrm{pH}$ and ferric chloride dosage were 99, 99.4, 98.6, 92.8, 93.5, 94.0 percent for initial turbidities of $10,50,100,200,500$ and 1000 NTU, respectively. The highest turbidity removal efficiency for ferric chloride was almost constant (more than $90 \%$ ) over the selected range of turbidity. Results showed that turbidity removal is dependent on $\mathrm{pH}$, coagulant dosage, as well as initial turbidity of water for both alum and ferric chloride. Variation of $\mathrm{pH}$ considerably affected turbidity removal. When $\mathrm{pH}$ was kept around its optimal value (5-6 for ferric chloride and 6-7 for alum) the highest turbidity removal was achieved.

It should be noted that rapid mixing parameters including time and intensity of mixing, as well as slow mixing parameters may also affect turbidity removal efficiency in coagulation process. Rossini et al. (1999) studied the effect of mixing parameters on turbidity removal from tannery wastewater and highly turbid synthetic water (Rossini et al., 1999). They found that high turbidity removal can be achieved both with a short mixing time (about $10 \mathrm{~s}$ ) and a long mixing time $(60-90 \mathrm{~s})$. In literature there are rather contradictory recommendations for rapid mix parameters. Some 
researchers suggest long mixing time of a few minutes whereas others recommend instantaneous mixing. Since mixing time is important factor affect turbidity removal efficiency it should be further investigated to obtain a better insight into its role for optimizing the coagulation process.

Results indicated that performance of ferric chloride was better than alum in all cases particularly for high turbidity waters, however, turbidity removal efficiency showed an almost similar pattern for both alum and ferric chloride. Coagulation and flocculation process is a primary and cost-effective process in water treatment plants which can effectively remove turbidity from low to high turbidity waters when operational condition is optimized. Optimization of $\mathrm{pH}$ and coagulant dose may increase the coagulation efficiency and reduce the sludge volume and subsequently sludge management costs.

Coagulant aids may improve coagulation process and turbidity removal. But it should be considered that coagulant aids should not increase water treatment costs significantly. Their accessibility and preparation procedure should also be considered when selecting a coagulant aid. Lime was selected as the coagulant aid in this study because it is easily accessible and widely used in water treatment industry in Iran as well as many other countries. Preliminary jar test experiments obtained the optimal level of $5 \mathrm{mg} \mathrm{L}^{-1}$ for lime. Lime was applied only at optimal $\mathrm{pH}$ values for both alum and ferric chloride. Table 2 indicated that lime $(5 \mathrm{mg}$ $\mathrm{L}^{-1}$ ), as a cost-effective coagulant aid, improved coagulation efficiency and turbidity removal to some extent when using in accompany with alum and ferric chloride. However, lime dosage should be carefully controlled and lowered in coagulation process due to the production of excess amounts of sludge, as considered in this research. As it can be observed in Table 2, the highest improvement in turbidity removal efficiency was found at $\mathrm{pH} 5$ for initial turbidity of 50 NTU when lime was applied in accompany with $10 \mathrm{mg}$ $\mathrm{L}^{-1}$ ferric chloride $(66.7 \%$ increase). In general, lime addition could not considerably increase turbidity removal efficiency in most cases; however, its application improved coagulation process to some extent. For instance, lime addition reduced residual turbidity from $0.3-0.1 \mathrm{mg} \mathrm{L}^{-1}$ and $1.4-0.9 \mathrm{mg} \mathrm{L}^{-1}$, respectively for water samples with initial turbidities of 10 and 50 NTU, at pH 5 and ferric chloride dosage of $10 \mathrm{mg} \mathrm{L^{-1 }}$. Make a decision on using lime as a coagulant aid strongly depends on accessibility of other types of coagulant aids and their costs as well as available legislations to limit sludge production and disposal in water treatment plants.

This study demonstrated that coagulation process can assure turbidity removal from low to medium turbidity waters effectively using relatively low levels of aluminum sulfate and ferric chloride (10-20 mg L $\mathrm{L}^{-1}$ ). Turbidity removal efficiency still remained high when the initial turbidities of water were 500 NTU and 1000 NTU, particularly for coagulation with ferric chloride. Variation of $\mathrm{pH}$, coagulant dosage and initial turbidity of water found to be important factors affect turbidity removal efficiency. Both alum and ferric chloride demonstrated promising performance in turbidity removal from water.

\section{CONCLUSION}

The jar test experiments were performed on low to high turbidity waters. The coagulation experiments using aluminum sulfate and ferric chloride indicated that coagulation process effectively removed turbidity from water using 10-20 mg L $\mathrm{m}^{-1}$ of the used coagulants. The optimum $\mathrm{pH}$ range for turbidity removal was found 5-6 and 6-7, respectively, for ferric chloride and alum resulting in the maximum turbidity removal. The highest turbidity removal efficiency was within 82.999.0 and $92.9-99.4 \%$, respectively for alum and ferric chloride over the applied range of turbidity. Generally results showed that turbidity removal efficiency was higher for ferric chloride compared to aluminum sulfate at optimum conditions. Turbidity removal efficiency was sufficient to meet national drinking water limits of Iran (5 NTU) at optimum alum and ferric chloride dose for waters with initial turbidity of 10-100 NTU. Using 5 $\mathrm{mg} \mathrm{L}^{-1}$ lime as a coagulant aid could improve turbidity removal in some cases. Application of different dosage and alternative coagulants to meet allowable limits should be further studied. However, national standards vary among different countries.

Here, the coagulation process and turbidity removal was considerably affected by $\mathrm{pH}$, coagulant dosage, as well as initial turbidity of water for both alum and ferric chloride. Turbidity removal was relatively stable at all selected dosages greater than 10 mg L ${ }^{-1}$ when $\mathrm{pH}$ was kept constant, whereas turbidity removal using both used coagulants is seemed to be more influenced by $\mathrm{pH}$ variation than coagulant dosage. Investigating the influence of rapid mixing parameters, time and intensity of mixing, as well as slow mixing parameters on turbidity removal by alum and ferric chloride is also suggested for future studies. 


\section{ACKNOWLEDGMENT}

Special thanks to the Vice President Office for Research of Shahid Beheshti University as well as the Vice President Office for research of University of Tehran for their financial support.

\section{REFERENCES}

Annadurai, G., S.S. Sung and D.J. Lee, 2004. Simultaneous removal of turbidity and humic acid from high turbidity stormwater. Adv. Environ. Res., 8: 713-725. DOI: 10.1016/S1093.0191(03)00043.1

Diaz, A., N. Rincon, A. Escorihuela, N. Fernandez and E. Chacin et al., 1999. A preliminary evaluation of turbidity removal by natural coagulants indigenous to Venezuela. Proc. Biochem., 35: 391-395. DOI: 10.1016/S0032.9592(99)00085.0

Driscoll, C.T., D. Raymond and D. Letterman, 1998. Chemistry and fate of $\mathrm{Al}(\mathrm{III})$ in treated drinking water. J. Environ. Eng., 114: 21-37. DOI: 10.1061/ASCE.0733.9372.1988

Faiku, F., A.I. Haziri and H. Faiku, 2010. Extraction of $\mathrm{Ca}$ (II) and $\mathrm{Mg}$ (II) from Hydrochloric Acid Solutions by N,N-Dioctyl-1-Octanamine in Methyl Isobutyl Ketone. Am. J. Applied Sci., 7: 10431046. DOI: 10.3844/ajssp.2010.1043.1046

Ghaly, A.E., A. Snow and B.E. Faber. 2007. Effective coagulation technology for treatment of grease filter washwater. Am. J. Environ. Sci., 3: 19-29. DOI: 10.3844/ajessp.2007.19.29
Guida, M., M. Mattei, C. Della Rocca, G. Melluso and S. Meric, 2007. Optimization of alumcoagulation/flocculation for COD and TSS removal from five municipal wastewater. Desalination, 211: 113-127. DOI: 10.1016/j.desal.2006.02.086

Kang, L.S. and J.L. Cleasby, 1995. Temperature effects on flocculation kinetics using Fe(III) coagulant. J. Environ. $\quad$ Eng., 121: 893-901. 10.1061/ASCE.0733.9372.1995

Rossini, M., J.G. Garrido and M. Galluzzo, 1999. Optimization of the coagulation-flocculation treatment: Influence of rapid mix parameters. Water Res., 33: 1817-1826. DOI: 10.1016/S0043.1354.98.00367.4

Shen, Y.H., 2005. Treatment of low turbidity water by sweep coagulation using bentonite. J. Chem. Technol. Biot., 80: 581-586. DOI: $10.1002 /$ jctb. 1244

Volk, C., K. Bell, E. Ibrahim, D. Verges, G. Amy and M. Lechevaller, 2000. Impact of enhanced and optimized coagulation on removal of organic matter and its biodegradable fraction in drinking water. Water Res., 34: 3247-3257. DOI: 10.1016/S0043-1354.00.00033.6

Yukselen, M.A. and J. Gregory, 2004. The effect of rapid mixing on the break-up and re-formation of flocs. J. Chem. Technol. Biot., 79: 782-788. DOI: $10.1002 /$ jctb. 1056 